\title{
Congenital fetal anomalies in Kuwaiti women with gestational and pre- gestational diabetes and its relation to self-blood glucose monitor
}

Ali M. Mahmoud1, Abdulnabi T. Alattar2, Ibrahim A. bdelazim3, Khloud A. Abdallah4 1Department of Internal Medicine, Al Azahar University, Egypt. 2Department of Internal Medicine, Amiri Hospital, Kuwait. 3Department of of Obstetrics and Gynecology, Ain Shams University, Egypt. 4Diabetologist at Dasman Diabetes Institute, Kuwait

Background: Diabetes during pregnancy associated with increased risk of congenital fetal anomalies. Objectives: This study designed to evaluate the prevalence of congenital fetal anomalies in Kuwaiti women with gestational and pre-gestational diabetes and its relation to self-blood glucose monitor.

Subjects and Methods: This prospective study was conducted in the Maternity hospital, Kuwait over one year. Women with gestational diabetes and pre-gestationaldiabetes The participants were asked to perform daily self-blood glucose monitor and the Glycosylated hemoglobin measured for the studied women in the first visit and monthly thereafter. The pregnancy and the neonatal outcomes collected and statistically analyzed using statistical package for social sciences version 20 (Chicago, IL, USA), Student's ttest and Chi-square test (X2) to evaluate the prevalence of congenital fetal anomalies in Kuwaiti women with gestational diabetes and pregestational diabetes and its relation to self-blood glucose monitor.
Results: The CFAs recorded in $23.2 \%(35 / 151)$ of the studied women. The recorded congenital fetal anomalies (CFAs) were cardiovascular in $7.4 \%(11 / 151)$,

musculoskeletal in $3.9 \%(6 / 151)$, urogenital in $3.3 \%$ (5/151), facial in $1.9 \%(3 / 151)$, central nervous system in $1.3 \%(2 / 151)$, gastrointestinal in $0.7 \%$ (1/151) and multiple CFAs in 4.6\% (7/151). The Relative Risk analysis showed that the risk of CFAs increased 43.8 times in women with uncontrolled blood sugar before conception $(\mathrm{P}<0.001), 8.7$ times in women with <4 SBGM per day during pregnancy $(\mathrm{P}<0.001)$ and 14.5 times in women with $\mathrm{HbA} 1 \mathrm{c} \geq 6.5 \%$ during first trimester $(\mathrm{P}<0.001)$.

\begin{tabular}{|c|c|}
\hline Congenital fetal anomalies & $\begin{array}{l}\text { Number and } \\
\text { percentage }\end{array}$ \\
\hline Cardiovascular system & $7.4 \%(11 / 151)$ \\
\hline Musculoskeletal system & $3.9 \%(6 / 151)$ \\
\hline Facial anomalies & $1.9 \%(3 / 151)$ \\
\hline Central nervous system & $1.3 \%(2 / 151)$ \\
\hline Gastrointestinal sysrem & $0.6 \%(1 / 151)$ \\
\hline Multiple CFAs anomalies & $4.6 \%(7 / 151)$ \\
\hline
\end{tabular}

Conclusion: Pre-conception counseling, optimum glycemic control before conception and during the first trimester can significantly lower the incidence of CFAs in pregnant women with GDM and PGDM. 